\title{
APLIKASI MENENTUKAN JENIS PERMAINAN UNTUK PERKEMBANGAN ANAK USIA 0-6 TAHUN
}

\author{
Elyza Gustri Wahyuni ${ }^{1)}$, Erna Retno Wukiratun ${ }^{2)}$ \\ Jurusan Teknik Informatika Fakultas Teknologi Industri Universitas Islam Indonesia, ${ }^{1,2)}$ \\ Jl. Kaliurang Km. 14,5 Sleman Yogyakarta, 55584 \\ E-Mail:elyza@uii.ac.id ${ }^{l)}$,ernaretnow@gmail.com ${ }^{2}$
}

\begin{abstract}
Growing up in children is one aspect that is taken seriously by the parents, because it is an aspect related to the formation of a person. The role of parents for child growth can also affect how their children develop. Parents have different ways of caring for their children and the games provided do not help the child's development be more optimal. Children who are detected to experience developmental delay need special attention, therefore training children through suitable and appropriate games can improve their development. So it takes an expert system of early detection to determine the type of game that is in accordance with the development of gross motor, fine motor, language, and social behavior in children aged 0 to 6 years. The results of this study indicate that the type of game that is applied as an exercise for child development is appropriate and can be used to assist in improving child development optimally.
\end{abstract}

Keywords : Child Growth, Game, Game Type, Expert System.

\section{PENDAHULUAN}

Pertumbuhan adalah suatu proses alamiah yang terjadi pada individu, yaitu secara bertahap, berat dan tinggi anak semakin bertambah dan secara simultan mengalami peningkatan untuk berfungsi baik secara kognitif, psikososial, maupun spiritual (Supartini, 2000). Setiap manusia mengalami pertumbuhan yang berbeda - beda, bisa mengalami kecepatan maupun keterlambatan tergantung pada individu dan juga lingkungannya. Periode terpenting dalam tumbuh kembang adalah masa balita, hal ini dikarenakan anak mengalami masa kritis dan diperlukam rangsangan / stimulasi untuk menyempurnakan fungsi setiap organ tubuhnya. Stimulasi ini dapat dilakukan sejak bayi baru lahir dan dapat dilakukan secara bertahap, berkelanjutan dan terus menerus. Dalam menilai kemajuan perkembangan anak dapat dilakukan dengan metode pengkajian yang digunakan secara luas yaitu dengan menggunakan Denver Developmental Screening Test (DDST).

DDST digunakan untuk mendeteksi adanya masalah dalam perkembangan anak usia 0-6 tahun, sehingga tes ini dapat mengidentifikasi anak yang memerlukan evaluasi lebih lanjut. Terdapat 4 aspek dalam perkembangan anak diantaranya perkembangan gerak kasar, perkembangan gerak halus, perkembangan bicara atau bahasa, dan perkembangan percaya diri atau perilaku sosial. Sehingga secara keseluruhan tes ini akan menghasilkan klasifikasi dalam kategori normal, abnormal, questionable atau untestable. Meskipun belum ada angka resmi, namun angka gangguan keterlambatan perkembangan anak di Indonesia cukup tinggi. Hal ini menjadi suatu kewaspadaan bagi setiap orang tua dalam mengawasi tumbuh kembang anak agar tidak mengalami gangguan keterlambatan pertumbuhan. Tahapan yang dilakukan dalam mengawasi perkembangan anak tentu tidak hanya sebatas deteksi dini melalui DDST, melainkan bagaimana cara melatih anak kategori normal lebih diasah kecerdasannya melalui permainan dan anak kategori abnormal atau gangguan perilaku dapat segera diatasi dengan terapi.

Sistem Pakar adalah suatu program komputer yang dirancang untuk memodelkan kemampuan penyelesaian masalah yang dilakukan oleh seorang pakar. Sistem Pakar (Expert System) dibuat 
bertujuan untuk dapat menyelesaikan masalah yang cukup rumit yang sebenarnya hanya bisa diselesaikan oleh para ahli (Kusumadewi, Sri, 2003). Metode yang dapat digunakan dalam sistem pakar salah satunya adalah certainty factor, metode ini banyak digunakan dalam mengdiagnosis sesuatu yang belum pasti. Certainty factor ini sendiri merupakan nilai klinis yang diberikan pakar untuk menunjukan tingkat kepercayaan.

Dari uraian diatas maka dapat dikembangkan penerapan sistem pakar dengan metode certainty factor dalam menentukan jenis permainan untuk perkembangan motorik, bahasa, dan perilaku sosial pada anak usia 0-6 tahun.

\section{STUDI LITERATUR}

Penelitian sebelumnya yang sudah dilakukan oleh delima R., dkk mengenai Identifikasi Kebutuhan Pengguna Untuk Aplikasi Permainan Edukasi Bagi Anak Usia 4 sampai 6 Tahun, dalam penelitian ini bertujuan untuk melihat komponen utama apa saja yang harus terpenuhi dalam membangun aplikasi permainan edukasi untuk anak usia 4 sampai 6 tahun, disini disebutkan proses pengumpulan informasi untuk definisi kebutuhan pengguna dilakukan dengan menggunakan metode wawancara, diskusi, observasi dan kuisioner dari beberapa pakar psikolog tumbuh kembang anak, Guru TK dan Orang tua. Hasil penelitian ini dapat merumuskan standar permainan yaitu ada 26 kriteria yang harus terpenuhi dan dikelompokkan menjadi 6 standar aplikasi.

Penelitian berikutnya yaitu mengenai "Sistem Pakar Untuk Menentukan Tipe Autisme Pada Anak Usia 7-10 Tahun Menggunakan Metode Forward Chaining" (Setiaji A.,K., 2013) disini dijelaskan bahwa Autisme merupakan salah satu gangguan tumbuh kembang anak yang sangat penting untuk ditangani secara dini, metode yang digunakan yaitu dengan rule base forward chaining untuk mengetahui tipe autism yang dialami seorang anak, kelemahan penelitian ini tidak dijelaskan gejala Autisme nya dan macam - macam jenis Autisme apa saja, hanya ditampilan akhir dijelaskan bahwa sistem dapat memberikan keluaran berupa jenis autisme yang diderita anak dengan terapi perilaku dan pengobatan secara umum, untuk kevalidan hasil dengan pengetahuan pakar tidak dijelaskan karena tidak ada uji validitasnya.

Penelitian lainnya yang juga membahas mengenai gangguan perkembangan anak dengan metode ketidakpastian yaitu Dempster-Shafer (Okfalisa dan Novita, M, 2013) dijelaskan bahwa terdapat 80 gejala gangguan perkembangan anak dengan diagnosa 12 jenis gangguan perkembangan, dihasil penelitian juga dijelaskan bahwa sistem diujikan dengan 11 pasien dan hasilnya dicocokkan dengan pengetahuan psikiater yang mendapatkan hasil $82 \%$, terapi yang dijelaskan disistem sudah bagus hanya saja kurang detail langkah - langkah yang sebaiknya dilakukan oleh pengguna sistem untuk penanganan secara dini. kekurangan penelitian ini tidak dijelaskan berapa batasan umur anak yang dimaksud dalam uji sistem.

Dari beberapa penelitian sebelumnya maka penelitian ini mencoba untuk memperbaharui aspek yang ingin diteliti yaitu mengenai menentukan jenis permainan yang tepat untuk anak usia 0-6 tahun, karena dengan melihat beberapa penelitian sebelumnya juga dikatakan bahwa deteksi dini tumbuh kembang anak jika terdapat gangguan dalam perkembangannya akan sangat membantu agar tidak terjadi keterlambatan atau gangguan perkembangan lainnya. Mengacu kepada penelitian sebelumnya juga metode yang diterapkan menggunakan metode ketidakpastian yaitu Certainty Factor karena terdapat banyak kemungkinan jenis permainan berdasarkan tahapan perkembangannya, maka lebih cocok menggunakan metode ketidakpastian. 


\section{METODOLOGI PENELITIAN}

\subsection{SISTEM PAKAR}

Sistem pakar (expert system) adalah sistem yang berusaha mengadopsi pengetahuan manusia ke komputer, agar komputer dapat menyelesaikan masalah seperti yang biasa dilakukan oleh para ahli (Giarratano, J. and Riley G, 2005). Atau dengan kata lain sistem pakar adalah sistem yang didesain dan diimplementasikan dengan bahasa pemrograman tertentu untuk dapat menyelesaikan masalah seperti yang dilakukan para ahli. Tujuan utama sistem pakar bukan untuk menggantikan kedudukan seorang ahli atau seorang pakar, tetapi hanya untuk memasyarakatkan pengetahuan dan pengalaman dari para pakar. Seiring pertumbuhan populasi manusia, maka dimasa yang akan datang sistem pakar ini diharapkan sangat berguna membantu dalam hal pengambilan keputusan (Turban, E, 1995).

Sistem pakar disusun oleh dua bagian utama, yaitu lingkungan pengembang dan lingkungan konsultasi (Martin, J., and Oxman, S, 1998). Lingkungan pengembang sistem pakar digunakan untuk memasukkan pengetahuan pakar kedalam lingkungan sistem pakar, sedangkan lingkungan konsultasi digunakan oleh pengguna yang bukan pakar untuk memperoleh pengetahuan pakar.

Sistem pakar memiliki beberapa komponen utama yaitu: antar muka pengguna (user interface), basis data sistem pakar (expert system database), fasilitas akuisisi pengetahuan (knowledge acquisition facility) dan mekanisme inferensi (inference mechanism). Selain itu ada satu komponen yang ada pada beberapa sistem pakar yaitu fasilitas penjelasan (explanation facility) (Turban, E, 2005).
Pengambilan keputusan pada sistem pakar menggunakan penalaran non monotonis. Penalaran non monotonis adalah suatu penalaran dimana terdapat penambahan fakta baru yang dapat menggugurkan fakta - fakta sebelumnya sehingga mengakibatkan ketidak konsistenan. Ciri - ciri penalaran non monotonis adalah :

1. Mengandung ketidakpastian.

2. Adanya perubahan pada pengetahuan.

3. Adanya penambahan fakta baru sehingga mengubah konklusi sebelumnya.

Sedangkan penalaran monotonis memiliki ciri - ciri konsisten dan pengetahuannya lengkap dalam Kusumadewi

\subsection{Certanty Factor (CF)}

Certainty Factor merupakan salah satu metode yang digunakan untuk penalaran non monotonis. Faktor kepastian (certainty factor) menyatakan kepercayaan dalam sebuah kejadian atau fakta (hipotesis) berdasarkan bukti atau penilaian pakar (Turban, E, 2005). Certainty factor menggunakan suatu nilai untuk mengasumsikan derajat keyakinan seorang pakar terhadap suatu data. Faktor kepastian (Certaity Factor) diperkenalkan oleh Shortliffe Buchanan dalam pembuatan MYCIN (Kusumadewi, Sri, 2003). Notasi faktor kepastian :

$\mathrm{CF}[\mathrm{h}, \mathrm{e}]=\mathrm{MB}[\mathrm{h}, \mathrm{e}]-\mathrm{MD}[\mathrm{h}, \mathrm{e}]$ 
Dengan :

$\mathrm{CF} \quad[\mathrm{h}, \mathrm{e}]=$ Certainty Factor Hipotesa yang dipengaruhi oleh evidence $e$ diketahui dengan pasti.

MB [h,e] = Measure of Belief, ukuran kepercayaan terhadap hipotesa $h$, jika dipengaruhi evidence $e$ (antara 0 dan 1).

MD $[\mathrm{h}, \mathrm{e}]=$ Measure of Disbelif, ukuran ketidakpercayaan terhadap hipotesa h, jika dipengaruhi evidence e (antara 0 \& 1$)$.

1. Beberapa evidence dikombinasikan untuk menentukan CF dari suatu hipotesis (gambar 1.a). Jika $\mathrm{e}_{1}$ dan $\mathrm{e}_{2}$ adalah observasi, maka :

$M B\left[h, e_{1} \wedge e_{2}\right]=\left\{\begin{array}{c}0 \\ M B\left[h, e_{1}\right]+M B\left[h, e_{2}\right] .\left(1-M B\left[h, e_{1}\right]\right)\end{array}\right\}$

$M D\left[h, e_{1} \wedge e_{2}\right]=\left\{\begin{array}{c}0 \\ M D\left[h, e_{1}\right]+M D\left[h, e_{2}\right] .\left(1-M D\left[h, e_{1}\right]\right)\end{array}\right\}$
2. CF dihitung dari kombinasi beberapa hipotesis (gambar 1.b). jika $\mathrm{h}_{1}$ dan $\mathrm{h}_{2}$ adalah hipotesis, maka :

$M B\left[h_{1} \wedge h_{2}, e\right]=\min \left(M B\left[h_{1}, e\right], M B\left[h_{2}, e\right]\right) \ldots(4)$

$M B\left[h_{1} \vee h_{2}, e\right]=\max \left(M B\left[h_{1}, e\right], M B\left[h_{2}, e\right]\right) \ldots(5)$

$M D\left[h_{1} \wedge h_{2, e}\right]=\min \left(M D\left[h_{1}, e\right], M D\left[h_{2}, e\right]\right) . .(6)$

$M D\left[h_{1} \vee h_{2}, e\right]=\max \left(M D\left[h_{1}, e\right], M D\left[h_{2}, e\right]\right) . .(7)$

3. Beberapa aturan saling bergandengan, ketidakpastian dari suatu aturan menjadi input untuk aturan yang lainnya (gambar 1.c), maka :

$\operatorname{MB}[\mathrm{h}, \mathrm{s}]=\mathrm{MB}^{\prime}[\mathrm{h}, \mathrm{s}] * \max (0, \mathrm{CF}[\mathrm{s}, \mathrm{e}]) \ldots .(8)$

MB' $[\mathrm{h}, \mathrm{s}]=$ ukuran kepercayaan $\mathrm{h}$ berdasarkan keyakinan penuh terhadap validitas $\mathrm{s}$.

Kombinasi aturan ketidakpastian ada 3 hal, antara lain (Kusumadewi, Sri, 2003)

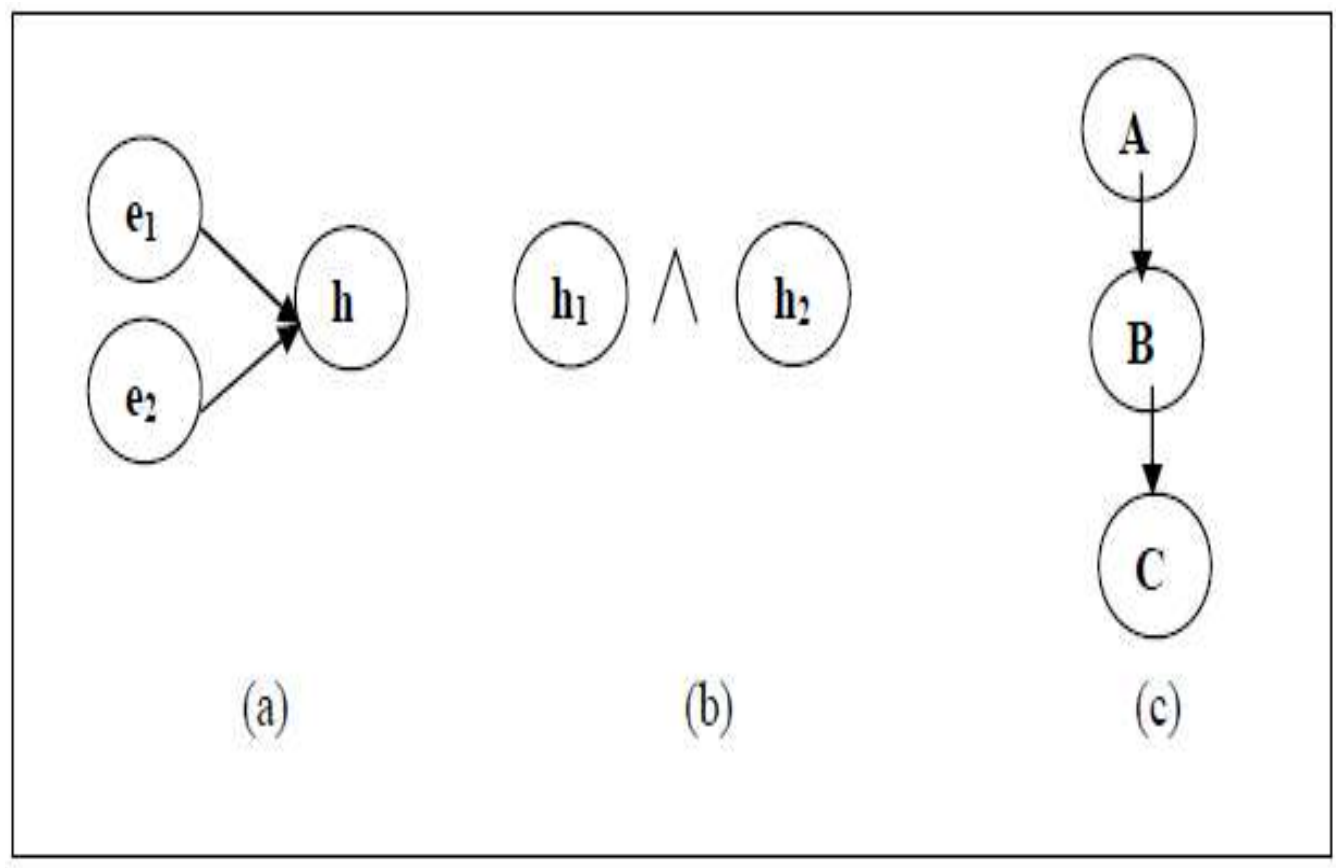

Gambar 1. Kombinasi Aturan Ketidakpastian. 


\subsection{Tes Denver II}

Denver Developmental Screening Test (DDST) adalah salah satu metode screening terhadap kelainan perkembangan anak. Tes ini bukanlah tes diagnostik atau tes IQ (Soetjiningsih, 1995). Dengan melakukan pengkajian untuk menilai kemajuan perkembangan anak usia 0-6 tahun, tes denver ini mendeteksi adanya masalah dalam perkembangan anak.

Tes denver memiliki 4 sektor yang menjadikan aspek yang saling berpengaruh dalam tumbuh kembang, diantaranya :

1. Motorik Halus

Sektor motorik halus terkait dalam aspek yang berhubungan dengan kemampuan anak dalam mengamati sesuatu, melakukan gerakan yang melibatkan bagian - bagian tubuh tertentu dan dilakukan oleh otot - otot kecil.

2. Sektor Motorik Kasar

Sektor motorik kasar merupakan aspek yang berhubungan dengan pergerakan dan sikap tubuh.

3. Sektor Bahasa

Sektor bahasa merupakan aspek yang berkaitan dengan kemampuan dalam berkomunikasi dan juga respon terhadap suara, mengikuti perintah dan berbicara secara spontan.

4. Sektor Perilaku Sosial

Sedangkan aspek dari sektor perilaku sosial lebih cenderung terhadap kemampuan mandiri, bersosialisasi dan berinteraksi dengan lingkungannya.

Penilaian akan diberikan pada setiap item tugas dengan skor sesuai usia anak dalam tes ini, ketentuan penilaian yaitu lulus / P / Pass, Gagal / F / Fail, Menolak / R / Refusal dan Tidak Ada Kesempatan / NO / No Opportunity. Dalam keseluruhan tes denver akan menghasilkan diagnosa perkembangan anak yang tergolong dalam 4 kategori yaitu normal, abnormal, untestable, questionable.

\subsection{Tumbuh Kembang Anak}

Terdapat perbedaan definisi diantara pertumbuhan dan perkembangan dalam proses tumbuh kembang anak. Pertumbuhan (growth) berkaitan dengan masalah perubahan dalam ukuran fisik seseorang dan dapat dilihat dari pertambahan tinggi badan maupun berat badannya. Sedangkan perkembangan (development) berkaitan dengan pematangan dan penambahan kemampuan (skill) fungsi organ atau individu. Kedua proses ini terjadi secara singkron pada setiap individu.

Beberapa penelitian menyebutkan bahwa masa usia dini merupakan metode kritis dalam perkembangan anak. Perkembangan kecerdasan anak berlangsung sangat pesat pada tahun-tahun awal kehidupannya. Sekitar $50 \%$ kapabilitas kecerdasan dimiliki anak berusia 4 tahun, $80 \%$ diperoleh ketika anak berusia 8 tahun, dan mencapai titik kulminasi ketika anak berusia 18 tahun (Jalal F, S., 2002).

\section{Permainan untuk melatih kecerdasan anak}

Permainan merupakan cara belajar yang menyenangkan karena dengan bermain anak-anak belajar sesuatu tanpa mempelajarinya. Apa yang dipelajarinya ini disimpan dalam pikirannya dan akan dipadukan menjadi satu kesatuan dengan pengalaman-pengalaman lain yang kadang tanpa disadari (Romlah, T, 2001).

Dari hasil penelitian dari para pakar, telah ditemukan bahwa ternyata bermain mempunyai manfaat yang sangat besar untuk tahap awal perkembangan anak. Aktivitas belajar anak yang dikemas dalam bentuk permainan akan membantu anak mencapai perkembangan yang utuh, baik secara fisik, intelektual, sosial, moral dan emosional anak. Terdapat jenis permainan diantaranya : 
a. Permainan sensoris / praktis

Permainan ini merupakan sepertiga dari kegiatan permainan anak prasekolah, tetapi kurang dari seperenam kegiatan permainan anak sekolah dasar. Dengan kata lain permainan praktis seringkali dilakukan oleh balita untuk melatih perkembangan sensori motor mereka. Jenis permainan disesuaikan dengan usia anak dan kemampuan mereka dalam melakukan gerakan seperti bermain bola, petak umpet, bermain loncat - loncatan, bermain air, dll.

b. Permainan pura - pura / simbolis

Dengan permainan simbolis anakanak akan belajar mentransformasikan benda - benda dengan menggantikan benda tersebut dengan benda lain dan memperlakukannya seperti benda yang digantikan. Permainan jenis ini dapat dilakukan dengan melakukan rumah - rumahan, masak - masakan, memerankan drama dengan boneka, dan lain - lain.

c. Permainan Sosial

Permainan sosial lebih melibatkan interaksi sosial tengan teman-teman sebayanya.Permainan ini juga dapat dilakukan dengan orang tua / pengasuh untuk meningkatkan komunikasi dan bahasa, sebagai contoh permainan yang dapat dilakukan dengan bernyanyi, menyebut nama - nama teman, menyebut benda - benda dengan gambar, dan lain - lain.

d. Permainan Konstruktif

Kegiatan yang dilakukan dalam permainan ini dapat melatih sensori halus dan mengkombinasikan secara berulang dengan representasi gagasan - gagasan simbolis. Permainan yang dapat dilakukan untuk meningkatkan perkembangan motorik halus seperti permainan puzzle, menata menara balok, bermain playdough, melipat kertas, dan lain - lain.

\section{e. Games}

Kegiatan - kegiatan games dilakukan untuk memperoleh kenikmatan yang melibatkan aturan dan seringkali kompetisi dengan satu orang atau lebih. Permainan ini dapat diterapkan sebagai perlombaan dengan mendapatkan suatu hadiah yang berkesan bagi anak, seperti lomba mengancingkan kancing baju, lomba menyikat gigi, dan lain - lain.

\section{Permainan sebagai Terapi}

Pada umumnya terapi dilakukan oleh seseorang untuk memulihkan kesehatan dari sakit yang diderita, dengan melakukan pengobatan ataupun perawatan kepada dokter atau spesialis.

Terapi bermain adalah bagian perawatan pada anak yang merupakan salah satu intervensi yang efektif bagi anak untuk menurunkan atau mencegah kecemasan sebelum dan sesudah tindakan operatif. Dengan demikian dapat dipahami bahwa didalam perawatan pasien anak, terapi bermain merupakan suatu kegiatan didalam melakukan asuhan keperawatan yang sangat penting untuk mengurangi hospitalisasi bagi pertumbuhan dan perkembangan anak selanjutnya (Nursalam, d, 2005).

Dalam perawatan pasien anak berikut adalah terapi yang dilakukan untuk mengatasi hambatan dalam tumbuh kembang anak dan meningkatkan kecerdasan :

\section{a. Fisioterapi}

Dalam fisioterapi melakukan analisis dan menetapkan program stimulasi dini dan intervasi perkembangan motorik kasar. Fisioterapi dilakukan untuk mengembangkan dan memulihkan gerak dan fungsi tumbuh, kemampuan fungsional tersebut diantaranya Tidur miring, Berguling, Merayap, Merangkak, Duduk, Berdiri. 
b. Terapi Wicara

Secara klinis banyak faktor yang dapat menghambat anak terlambat atau sulit berbicara seperti pekembangan otot yang lambat, kurangnya interaksi dengan orang lain, bahasa non verbal yang lebih dahulu berkembang, harapan / ekspetasi orang tua yang terlalu rendah, dan tidak banyak waktu untuk berbicara. Terapi wicara melakukan analisis dan menetapkan program stimulasi dini dan intervasi perkembangan bicara, terapi ini dapat dilakukan dengan berbagai macam cara diantaranya yaitu : Mengajak anak berbicara sejak lahir, atau dengan Melatih stimulasi alat oral salah satunya dengan melakukan gerakan lidah dan mulut seperti berdecak, mengecap, menggetarkan bibir.

c. Terapi Okupasi

Terapi okupasi dibutuhkan untuk anak - anak yang mengalami keterlambatan keterampilan motorik halus, terapi okupasi melakukan analisis dan menetapkan program stimulasi dini dan intervasi perkembangan motorik halus.
Terdapat 2 bentuk aktivitas yang dilakukan diantaranya : ADL (Activity Day Learning) yaitu memberikan keterampilan hidup mandiri misalnya dengan latihan menali sepatu, mengancingkan baju dan lain sebagainya, yang berikutnya Permainan yaitu terapi yang berbentuk bermain untuk memberikan kesenangan dan sosialisasi yang baik. Misalkan bermain lempar bola, menggambar, memotong dan melipat kertas, dan menyusun puzzle.

\section{HASIL DAN PEMBAHASAN \\ 4.1. Perancangan Sistem}

Use Case Diagram digunakan untuk menggambarkan fungsionalitas sistem serta proses interaksi yang dilakukkan antara aktor dengan sistem. Dalam perancangan sistem ini aktor yang dapat mengakses adalah admin dan pakar. Admin berperan sebagai user yang dapat mengelola user dan pakar yang telah terdaftar sebagai user dapat melakukan proses login. Selain itu juga Pakar dapat mengakses sistem dengan melakukan login terlebih dahulu, selanjutnya pakar dapat mengelola mengelola kondisi perkembangan anak, mengelola jenis permainan, mengelola data pertanyaan, mengelola data pasien, dan melihat hasil sebagai output dari proses memilih permainan berdasarkan kondisi anak / pasien. Use case diagram dapat dilihat pada gambar 2 .

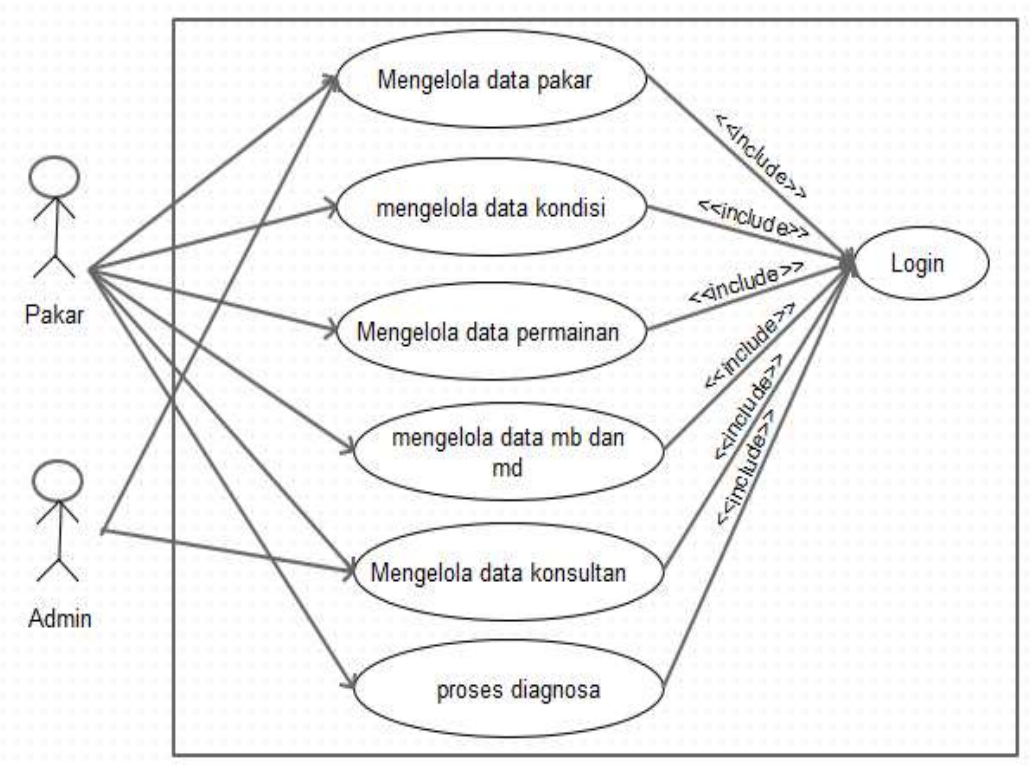

Gambar 2. Use Case Diagram. 
Tabel 1. Jenis Permainan Menurut Pakar

\begin{tabular}{|c|c|c|c|c|}
\hline \multirow{2}{*}{ USIA } & \multicolumn{4}{|c|}{$\begin{array}{c}\text { PERMAINAN } \\
\text { NORMAL }\end{array}$} \\
\hline & $\begin{array}{l}\text { MOTORIK } \\
\text { HALUS }\end{array}$ & $\begin{array}{l}\text { MOTORIK } \\
\text { KASAR } \\
\end{array}$ & BAHASA & $\begin{array}{l}\text { PERILAKU } \\
\text { SOSIAL } \\
\end{array}$ \\
\hline $4 \mathrm{bln}$ & Mainan gantung & Mainan gantung & $\begin{array}{c}\text { Mainan yang } \\
\text { mengeluarkan suara }\end{array}$ & \multirow[b]{2}{*}{$\begin{array}{c}\text { cilukba, kiss-bye, } \\
\text { mata genit }\end{array}$} \\
\hline 8 bln & $\begin{array}{c}\text { Mainan yang } \\
\text { dapat dipegang } \\
\text { dan digerakkan }\end{array}$ & $\begin{array}{c}\text { Mainan yang } \\
\text { dapat dipegang } \\
\text { dan digerakkan }\end{array}$ & $\begin{array}{c}\text { Mainan yang } \\
\text { mengeluarkan suara }\end{array}$ & \\
\hline $12 \mathrm{bln}$ & $\begin{array}{l}\text { Bermain Menara } \\
\text { balok / jelly } \\
\text { (berwarna-warni) }\end{array}$ & $\begin{array}{l}\text { Bermain } \\
\text { Melewati } \\
\text { terowongan }\end{array}$ & $\begin{array}{l}\text { Menyanyi lagu } \\
\text { sederhana }\end{array}$ & $\begin{array}{l}\text { Bermain puzzle } \\
\text { sederhana }\end{array}$ \\
\hline $18 \mathrm{bln}$ & $\begin{array}{l}\text { Bermain } \\
\text { membentuk } \\
\text { Playdough }\end{array}$ & $\begin{array}{l}\text { Bermain dengan } \\
\text { benda yang dapat } \\
\text { ditarik dan di } \\
\text { dorong }\end{array}$ & $\begin{array}{l}\text { Menebak nama-nama } \\
\text { hewan dan benda } \\
\text { (pada gambar atau } \\
\text { video interaktif) }\end{array}$ & $\begin{array}{l}\text { Bermain petak } \\
\text { umpet }\end{array}$ \\
\hline $24 \mathrm{bln}$ & $\begin{array}{l}\text { Mewarnai dan } \\
\text { menggambar }\end{array}$ & $\begin{array}{l}\text { Bermain bola } \\
\text { (dapat ditendang } \\
\text { dan dilempar) }\end{array}$ & $\begin{array}{l}\text { Membacakan buku } \\
\text { cerita bergambar }\end{array}$ & $\begin{array}{l}\text { Lomba memakai } \\
\text { pakaian dan sikat } \\
\text { gigi }\end{array}$ \\
\hline 3 thn & $\begin{array}{c}\text { Bermain dengan } \\
\text { kertasberwarna } \\
\text { (menggunting, } \\
\text { melipat) }\end{array}$ & $\begin{array}{l}\text { Menari dengan } \\
\text { musik anak - } \\
\text { anak }\end{array}$ & $\begin{array}{l}\text { Bermain drama } \\
\text { imajinatif dengan } \\
\text { orangtua / teman }\end{array}$ & $\begin{array}{l}\text { Bermain drama } \\
\text { imajinatif dengan } \\
\text { orangtua / teman }\end{array}$ \\
\hline 4 thn & $\begin{array}{l}\text { Menggambar atau } \\
\text { melukis }\end{array}$ & & & $\begin{array}{l}\text { Bermain rumah- } \\
\text { rumahan / masak- }\end{array}$ \\
\hline 5 thn & $\begin{array}{c}\text { Pemandangan dan } \\
\text { manusia }\end{array}$ & Bersepeda & Bercerita & $\begin{array}{l}\text { masakan / } \\
\text { berdagang }\end{array}$ \\
\hline \multirow{2}{*}{ USIA } & \multicolumn{4}{|c|}{ ABNORMAL } \\
\hline & Terapi Okupasi & Fisioterapi & Terapi Wicara & Terapi perilaku \\
\hline $\begin{array}{l}0-8 \\
\text { bln }\end{array}$ & $\begin{array}{l}\text { Berenang dengan } \\
\text { pelampung }\end{array}$ & Pijat bayi & $\begin{array}{l}\text { Mendengarkan lagu } \\
\text { anak - anak }\end{array}$ & \multirow{2}{*}{$\begin{array}{c}\text { Berkomunikasi dan } \\
\text { Mengajak } \\
\text { tersenyum, dan } \\
\text { tertawa }\end{array}$} \\
\hline $\begin{array}{l}1-2 \\
\text { thn }\end{array}$ & $\begin{array}{l}\text { Konseling dengan } \\
\text { menggunakan bak } \\
\text { pasir }\end{array}$ & Streching dengan & $\begin{array}{c}\text { Melihat video } \\
\text { percakapan anak- } \\
\text { anak }\end{array}$ & \\
\hline 3 thn & $\begin{array}{l}\text { Konseling dengan } \\
\text { menggunakan }\end{array}$ & $\begin{array}{l}\text { menggunakan } \\
\text { bola besar }\end{array}$ & $\begin{array}{l}\text { Streching mulut } \\
\text { (bermain gelembung, } \\
\text { meniup lilin) }\end{array}$ & \multirow{2}{*}{$\begin{array}{l}\text { Bermain rumah - } \\
\text { rumahan, masak- } \\
\text { masakan, } \\
\text { berdagang }\end{array}$} \\
\hline 4 thn & tanah liat & $\begin{array}{l}\text { Berjalan digaris } \\
\text { lurus }\end{array}$ & $\begin{array}{c}\text { Tebak gambar atau } \\
\text { benda miniatur }\end{array}$ & \\
\hline $\begin{array}{l}5-6 \\
\text { thn }\end{array}$ & $\begin{array}{l}\text { Melempar bola } \\
\text { kedalam lubang }\end{array}$ & $\begin{array}{l}\text { Bermain di } \\
\text { trampoline }\end{array}$ & bernyanyi & $\begin{array}{c}\text { Bermain dan } \\
\text { berkenalan dengan } \\
\text { oranglain / teman }\end{array}$ \\
\hline
\end{tabular}


Gambar 3 menunjukkan flowchart sistem pakar dalam menentukan jenis permainan untuk perkembangan motorik, bahasa dan perilaku sosial pada anak usia 0-6 tahun.

\subsection{Model Keputusan}

Tahap perkembangan menurut pakar dokter spesialis anak Dr. Sri Wahyuni, SpA digolongkan menjadi 8 golongan tingkatan umur, untuk setiap sektor tumbuh kembang anak diklasifikasikan masing - masing. Dari data tabel 1 jenis permainan berdasarkan usia, dapat dirumuskan aturan yang sesuai untuk menentukan jenis permainan yang tepat. Berikut ini merupakan beberapa aturan dari pakar dan yang sering digunakan untuk menentukan jenis permainan berdasarkan sektor pertumbuhan motorik halus :

1. Usia 4 Bulan

IF usia 4 Bulan AND Kondisi 1 Ya

THEN Permainan 1 (normal) ELSE

Permainan 8 (Terapi)

2. Usia 8 Bulan

IF usia 8 Bulan AND Kondisi $1 \mathrm{Ya}$

AND Kondisi 2 Ya

THEN Permainan 2 (normal) ELSE

Permainan 8 (terapi)

3. Usia 12 Bulan

IF usia 12 Bulan AND Kondisi 2 Ya

AND Kondisi 3 Ya

THEN Permainan 3 (normal) ELSE

Permainan 9 (terapi)

4. Usia 18 Bulan

IF usia 18 Bulan AND Kondisi 3 Ya

AND Kondisi 4 Ya

THEN Permainan 4 (normal) ELSE

Permainan 9 (terapi)
5. Usia 24 Bulan

IF usia 24 Bulan AND Kondisi 4 Ya

AND Kondisi 5 Ya

THEN Permainan 5 (normal) ELSE

Permainan 9 (terapi)

6. Usia 36 Bulan

IF usia 36 Bulan AND Kondisi 5 Ya

AND Kondisi $6 \mathrm{Ya}$

THEN Permainan 6 (normal) ELSE

Permainan 10 (terapi)

7. Usia 48 Bulan

IF usia 48 Bulan AND Kondisi 6 Ya

AND Kondisi $7 \mathrm{Ya}$

THEN Permainan 7 (normal) ELSE

Permainan 10 (terapi)

8. Usia 60 Bulan

IF usia 60 Bulan AND Kondisi 7 Ya

AND Kondisi 8 Ya

THEN Permainan 8 (normal) ELSE

Permainan 11 (terapi)

9. Status Normal/Abnormal

IF Permainan Motorik Kasar = Terapi AND Permainan Motorik Halus $=$ Terapi AND Permainan Bahasa $=$ Terapi AND Permainan Perilaku Sosial $=$ Terapi THEN abnormal ELSE normal.

Pertumbuhan anak dinyatakan abnormal jika anak tidak mampu melakukan semua kondisi (motorik halus, motorik kasar, bahasa maupun perilaku sosial) ditahapan pertumbuhan berdasarkan usianya. 
Aturan - aturan tersebut ditetapkan untuk mendapatkan nilai MB dan MD untuk memenuhi kebutuhan sistem dalam menentukan nilai CF. Sehingga sistem pakar yang dibuat dapat menentukan jenis permainan yang tepat untuk melatih kebutuhan anak dalam perkembangannya.
Tabel 2 Adalah tabel relasi jenis permainan dan tahap perkembangan dengan nilai MB dan nilai MD disektor Motorik Halus yang didapatkan berdasarkan penelitian terhadap pakar (Sumber: Dr. Sri Wahyuni, SpA).

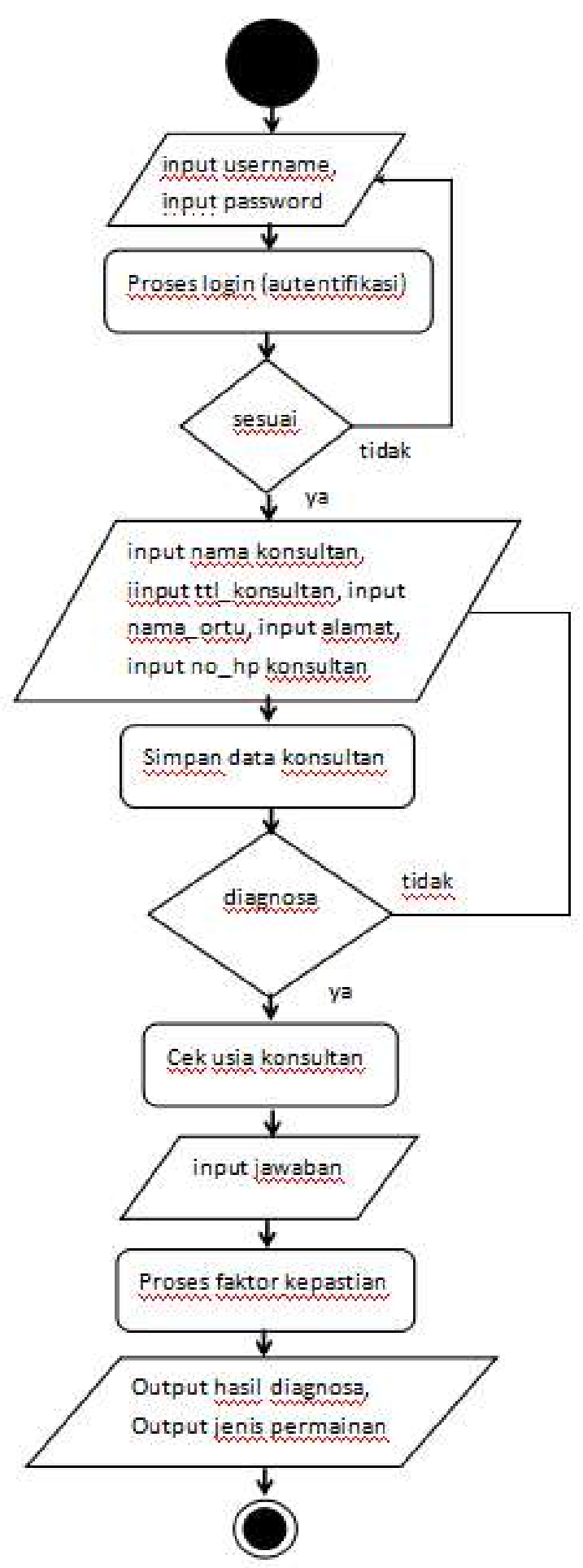

Gambar 3. Flowchart Sistem. 
Tabel 2. Relasi Jenis Permainan dan Tahap Perkembangan Anak (Sektor Motorik Halus)

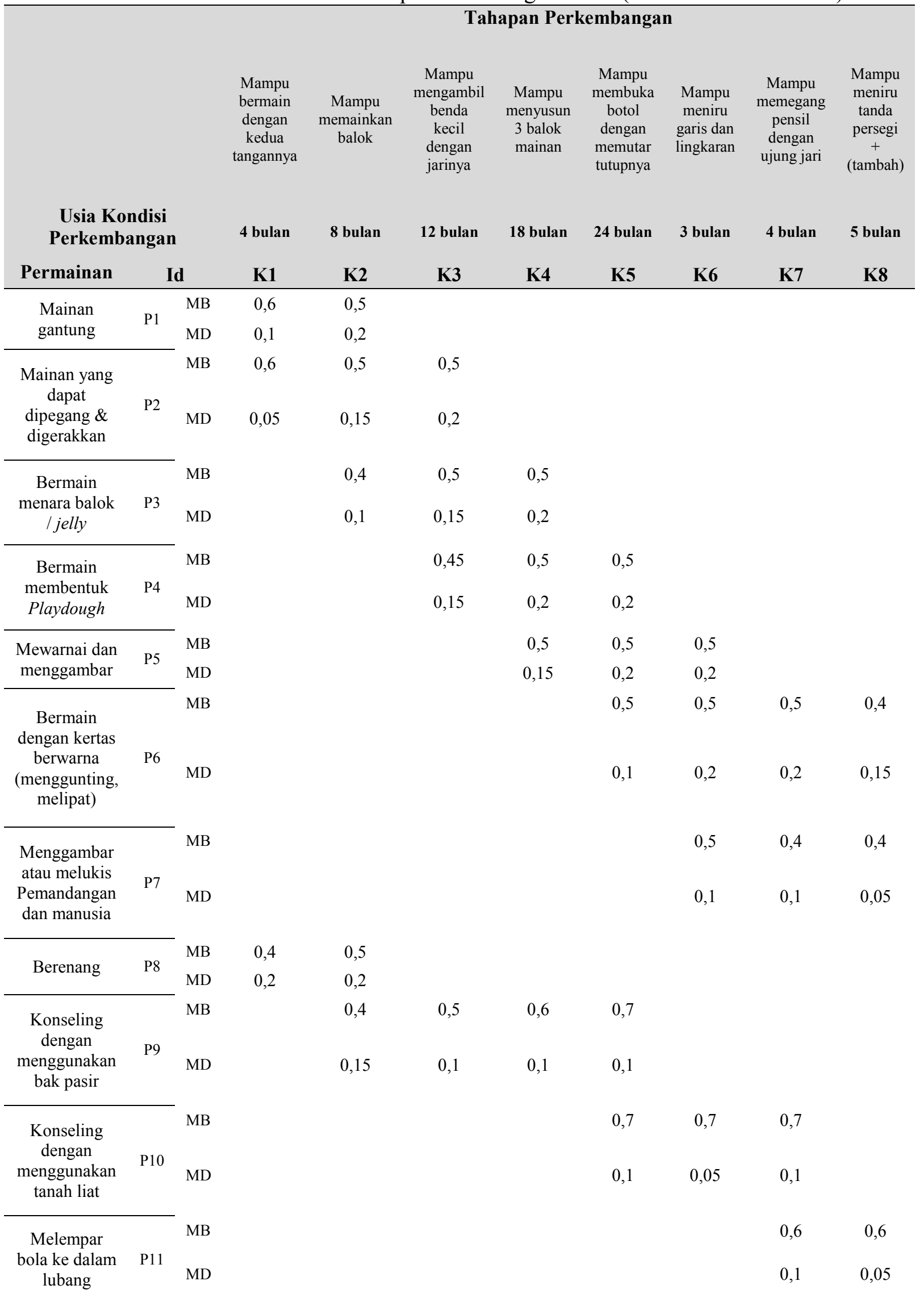




\subsection{Analisis Pengujian Sistem}

Pengujian data terhadap pasien dilakukan untuk menghitung keakuratan sistem berdasarkan kasus dari beberapa anak. Dengan memasukan nilai berdasarkan pertanyaan yang diajukan guna mengetahui seberapa besar kesalahan yang muncul dalam sistem.

Langkah pertama setelah data pasien dimasukkan secara lengkap dan tersimpan di sistem, kemudian sistem langsung melakukan filterisasi berdasarkan usia pasien. Setelah usia pasien diketahui maka sistem langsung memberikan pertanyaan kepada pasien melalui orangtua atau pengasuh. Pertanyaan - pertanyaan ini mewakilkan kondisi anak berdasarkan usianya dan terdapat 8 pertanyaan, disetiap pertanyaan ini disediakan jawaban untuk "ya" dalam arti anak mampu melakukan kondisi tertentu dan "tidak" sebagai jawaban ketika anak tidak mampu melakukan kondisi tertentu di usianya.

Contoh untuk pasien bernama Shira Nathania azaria saat ini berusia 11 bulan, berdasarkan usia nya maka pertanyaan yang diajukan adalah sebagai berikut yang dapat ditunjukkan pada gambar 4. Jawaban dari keseluruhan pertanyaan kemudian disimpan dan melewahi perhitungan certainty factor.

Pertanyaan yang ditunjukkan pada gambar 4 dihasilkan dari informasi kondisi pasien bahwa anak tersebut dapat melakukan semua kondisi diusianya dan hasil diagnosis ditunjukan pada gambar 5 .

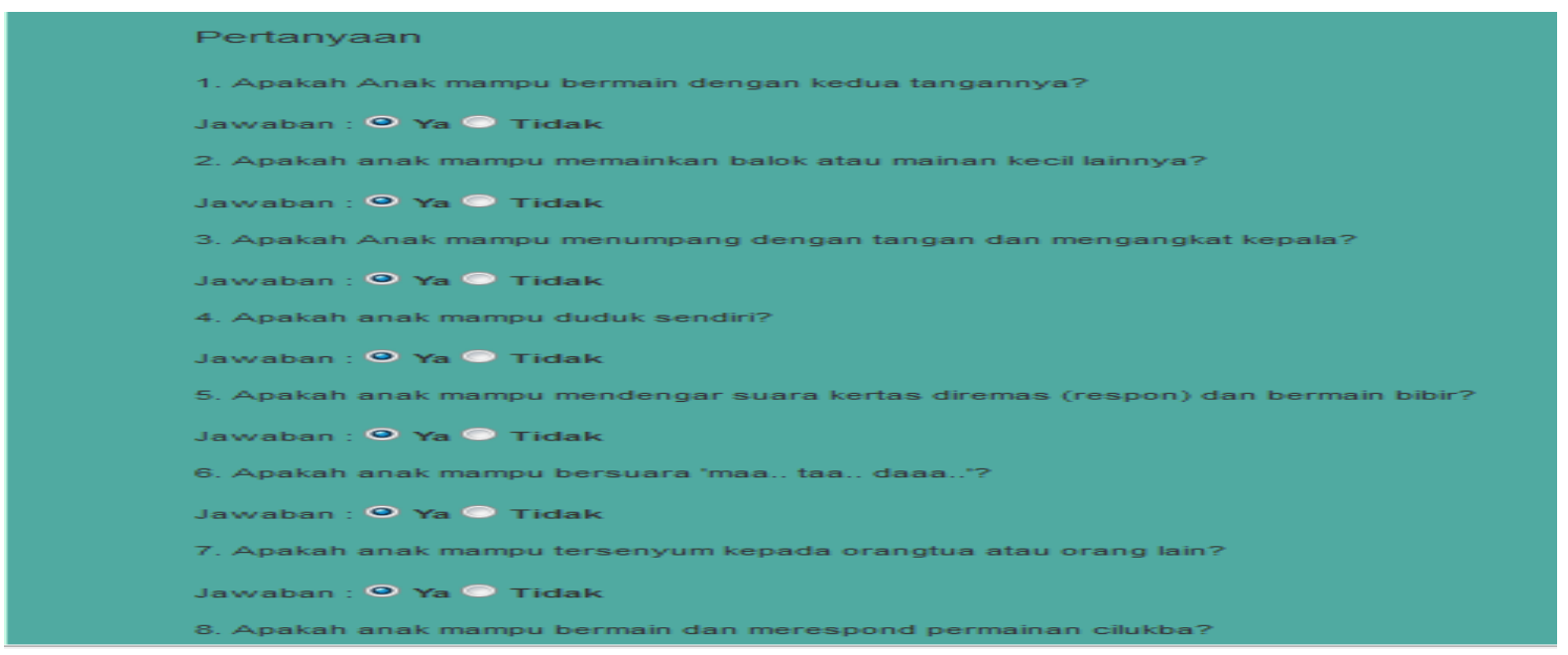

Gambar 4. Pertanyaan Diagnosis Pasien.

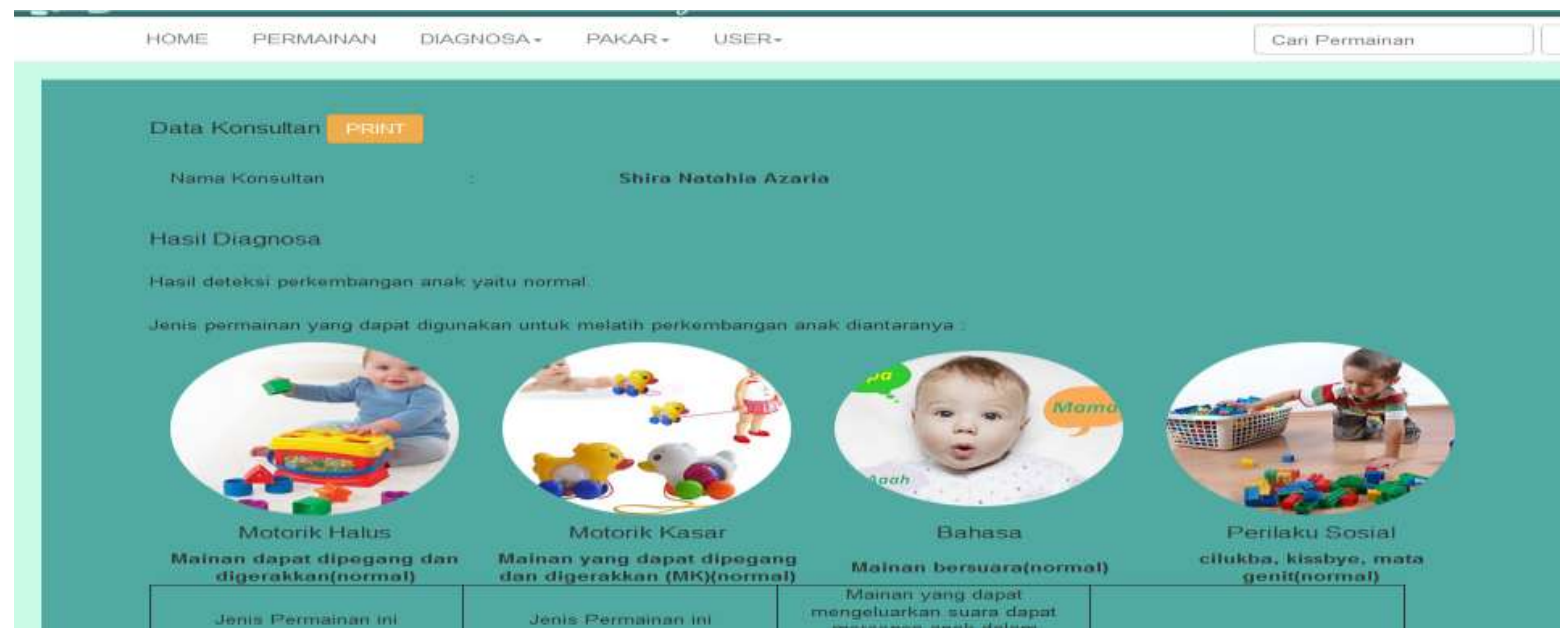

Gambar 5. Hasil Diagnosis Pasien. 
Disimpulkan bahwa anak dalam keadaan normal dan mampu melakukan kegiatan disemua kondisi diusianya dan hasil diagnosa sistem ini di sinkronkan dengan pengetahuan pakar yaitu dokter spesialis anak yang mengatakan bahwa untuk kondisi anak Shira Nathania Azaria umur 11 bulan ini memang tepat bahwa anak dalam keadaan normal dan jenis permainan yang tepat adalah permainan yang dapat dipegang dan digerakkan. Permainan ini dapat meningkatkan gerak motorik kasar dan motorik halus karena anak akan berusaha mengikuti gerak mainan dan berusaha menggapai mainan tersebut.

\subsection{Pengujian Pakar}

Setelah dilakukan pengujian sistem kepada pasien, kemudian juga dilakukan wawancara kepada pakar atas nama responden Dr. Sri Wahyuni, SpA. Wawancara ini dilakukan berdasarkan hasil diagnosis kepada beberapa pasien yang dilakukan sebelumnya. Beberapa pertanyaan yang diajukan kepada pakar dan disimpulkan bahwa jenis permainan yang sudah ada disistem sudah dapat membantu anak dalam meningkatkan tumbuh kembangnya, karena jenis permainan yang dapat dimainkan oleh organ tubuh yang lebih fokus ke otot tertentu saja sudah dapat dikatakan permainan itu bisa meningkatkan tumbuh kembang anak.
Ketika anak mengalami kesulitan berdiri maka yang harus dilatih yaitu pergerakan kaki dan permainan yang dipilih juga permainan yang dapat memfokuskan anak untuk menggerakan kakinya. Serta sistem ini sudah bisa dijadikan salah satu referensi untuk menentukan jenis permainan yang tepat sesuai dengan masa tumbuh kembang anak.

Selain itu sistem ini dapat membantu tenaga kesehatan untuk melakukan penentuan jenis permainan yang tepat agar dapat digunakan sebagai latihan guna membantu anak dalam meningkatkan perkembangan tubuhnya.

\section{KESIMPULAN}

Berdasarkan hasil penelitian serta pembahasan yang telah dilakukan, maka dapat disimpulkan :

1. Aplikasi Sistem Pakar ini mampu membantu kinerja pakar dalam menentukan jenis permainan untuk meningkatkan perkembangan motorik, bahasa dan perilaku sosial anak.

2. Setelah dilakukan pengujian keakuratan maka dapat disimpulkan bahwa sistem pakar memiliki kesesuaian berdasarkan perhitungan manual dan nilai dari pakar, sehingga hasil output sistem pakar cocok diterapkan untuk menentukan jenis permainan. 


\section{DAFTAR PUSTAKA}

Delima, R., Arianti, N. K., \& Pramudyawardani, B., 2015. Identifikasi Kebutuhan Pengguna Untuk Aplikasi Permainan Edukasi Bagi Anak Usia 4 sampai 6 Tahun. Jurnal Teknik Informatika Dan Sistem Informasi, 1.

Giarratano, J. and Riley G., 2005. Expert Systems : Principles and Programming, PWS Publishing Company, Boston.

Jalal F, S., 2002. Acuan Menu Pembelajaran pada pendidikan anak usia dini. Jakarta: PT. Rineka Cipta.

Kusumadewi, Sri., 2003. "Artificial intelligence (teknik dan aplikasinya)" Yogyakarta: Graha Ilmu.

Martin, J., and Oxman, S., 1988. Building Expert Systems : a tutorial, Prentice Hall, New Jersey.

Nursalam, d., 2005. Asuhan keperawatan bayi dan anak (untuk perawat dan bidan). Jakarta: Salemba Medika.

Okfalisa dan Novita, M., 2013. Rancang Bangun Diagnosa Gangguan Perilaku Abnormal Anak dengan Menggunakan Metode DempsterShafer. Jurnal Sains, Teknologi \& Industri SiTekIn.

Romlah, T., 2001. Teori dan Praktek Bimbingan Konseling. Jakarta: Ghalia Indonesia.
Setiaji A.,K., 2013. Sistem Pakar Untuk Menentukan Tipe Autisme Pada Anak Usia 7-10 Tahun Menggunakan Metode Forward Chaining. Jurnal Teknik Informatika UDINUS, 1-10.

Soetjiningsih., 1995. Tumbuh Kembang Anak. Jakarta: EGC.

Supartini., 2000. Buku Ajar Konsep Dasar Keperawatan Anak. Jakarta : EGC..

Turban, E., 1995. "Decision support and expert system; Management Support System" Newyork: Prentice-Hall.

Turban, E., 2005. “ Decision support system and intelligent systems ". Yogyakarta : Penerbit Andi. 